RESEARCH REPORT

\title{
Neighbourhoods and self rated health: a comparison of public sector employees in London and Helsinki
}

\author{
Mai Stafford, Pekka Martikainen, Eero Lahelma, Michael Marmot
}

J Epidemiol Community Health 2004;58:772-778. doi: 10.1136/jech.2003.015941

See end of article for authors' affiliations

Correspondence to:

Dr M Stafford,

International Centre for

Health and Society,

Department of

Epidemiology and Public

Health, University College

London Medical School,

1-19 Torrington Place,

London WC1E 6BT, UK.

m.stafford@public-health.

ucl.ac.uk

Accepted for publication 23 January 2004

\begin{abstract}
Study objective: Mortality and morbidity vary across neighbourhoods and larger residential areas. Effects of area deprivation on health may vary across countries, because of greater spatial separation of people occupying high and low socioeconomic positions and differences in the provision of local services and facilities. Neighbourhood variations in health and the contribution of residents' characteristics and neighbourhood indicators were compared in London and Helsinki, two settings where inequality and welfare policies differ.

Design: Data from two cohorts were used to investigate associations between self rated health and neighbourhood indicators using a multilevel approach.

Setting: London and Helsinki.

Participants: From the Whitehall II study (London, aged 39-63) and the Helsinki health study (aged 4060).

Main results: Socioeconomic segregation was higher in London than in Helsinki. Age and sex adjusted differences in self rated health between neighbourhoods were also greater in London. Independent of individual socioeconomic position, neighbourhood unemployment, proportion of residents in manual occupations, and proportion of single households were associated with health. In pooled data, residence in a neighbourhood with highest unemployment was associated with an odds ratio of less than good self rated health of 1.51 (95\% Cl 1.30 to 1.75). High rates of single parenthood were associated with health in London but not in Helsinki.

Conclusions: Neighbourhood socioeconomic context was associated with health in both countries, with some evidence of greater neighbourhood effects in London. Greater socioeconomic segregation in London may have emergent effects at the neighbourhood level. Local and national social policies may reduce, or restrict, inequality and segregation between areas.
\end{abstract}

across London. For example, $7 \%$ of all London dwellings are unfit to live in, ranging from $1.6 \%$ in an outer London borough to $18.3 \%$ in a borough in the east end. ${ }^{17}$ Over the past two decades, approaches to public housing management have tended to widen inequalities. There has been a policy of transferring public housing to the private sector through the "right to buy" (Housing Act 1980, 1984, 1986) and a strategy of offering the least popular properties to the "least deserving" tenants. ${ }^{18}$ Initiatives to broaden the diversity of household types within areas have not been widespread in the UK.

The metropolitan area of Helsinki, Finland, has a population of 965000 and covers $769 \mathrm{~km}^{2}{ }^{2}{ }^{19}$ Relatively deprived and affluent neighbourhoods can be distinguished, but local housing and city planning policies along with redistributive state policies have limited income inequalities in the country as a whole and locally. A stated aim of these policies has been to reduce socioeconomic segregation by building publicly funded housing and encouraging integration of different types of home ownership within areas. ${ }^{20}$ Income inequalities are larger in the UK than in Finland. ${ }^{21}$ Given the information suggesting greater socioeconomic segregation in London and a greater prominence of welfare state provision in Helsinki, we hypothesised that health differences between neighbourhoods and the effect of neighbourhood deprivation would be larger in London than Helsinki.

\section{DATA AND METHODS}

The data for this comparative study come from cohorts of public sector employees in London and Helsinki. and covers an area of $1500 \mathrm{~km}^{2}{ }^{16}$ There are substantial inequalities in unemployment, housing quality, and health 


\section{The London sample}

All civil servants aged 35-55 working in London offices at baseline (1985-8) were invited to participate in the Whitehall II study ${ }^{22}$ yielding a total of 10308 participants (response rate $73 \%$ ). The individual data used here were collected by self completion questionnaire at phase 3 (1991-3) as this coincided most closely with collection of the area level data. Participants living within the M25 (an orbital motorway encircling Greater London) were eligible. Those lost through sample attrition by phase $3(\mathrm{n}=1492)$, not living in the focus area $(\mathrm{n}=3173)$, or with missing socioeconomic or health data $(\mathrm{n}=342)$ were excluded giving a total sample of 5301 participants.

\section{The Helsinki sample}

Helsinki health study participants provide data for Helsinki (http://www.kttl.helsinki.fi/projektit/helsinki/helsinkitutkimus. htm). Municipal employees aged 40-60 working for the City of Helsinki in 2000-1 were invited to participate. With a response rate of $68 \%, 6243$ returned self completion questionnaires. According to non-response analysis, the data are reasonably representative of the target population. ${ }^{23}$ Participants living outside the Helsinki metropolitan area (municipalities of Helsinki, Espoo, Vantaa, and Kauniainen, $\mathrm{n}=1914$ ) or not having complete health, socioeconomic or area data $(n=42)$ were excluded leaving 4287 employees. The Helsinki and Whitehall II studies shared several instruments.

\section{Individual level measurement of health}

In both samples self rated health was obtained from the question "In general would you say your health is" with five responses ranging from excellent to poor. Self rated health reflects medical and other health information ranging from knowledge of existing diseases to cognitive and affective characteristics. ${ }^{24}$ It has good test-retest reliability, ${ }^{25}$ predicts mortality, ${ }^{26}$ and has been recommended for comparative purposes. ${ }^{27}$ The outcome was categorised as $0=$ excellent, very good, good, and $\mathrm{l}=$ fair and poor to examine "less than good health".

\section{Individual level measurement of socioeconomic position}

In both samples information on employment grade, our measure of socioeconomic position, was obtained using the following hierarchy: (1) managerial/administrative, (2) professional and semi-professional, (3) clerical, and (4) manual workers.

\section{Area level measurement}

In London, 1991 census data were used and census ward boundaries (average population 8000) defined neighbourhoods. In Helsinki, 2000 census data were used (with the exception of proportion of manual workers from the 1995 census). The classification used by the municipalities of Helsinki metropolitan area defined neighbourhoods (average population 4000). In both studies, neighbourhood areas are such that most residents could walk across in 15-20 minutes. These areas are used for the planning of amenities by local government and health service providers. We contend that these are suitable boundaries to define and compare neighbourhoods, although we note that administrative boundaries may not correspond to residents' experiences and perceptions.

Unemployment rates, proportion of single households, proportion of single parent households, and proportion of manual workers were used to describe neighbourhoods using the same definitions in London and Helsinki (table 1). These four indicators capture the socioeconomic characteristics of neighbourhoods (income is lower in single households and in single parent households) and were chosen for comparability between the two cities. Data on income and educational attainment were not easily comparable or reliable and were not included. Within each city, neighbourhoods were split into four equally sized groups (quartiles) for each neighbourhood indicator.

\section{Statistical methods}

The index of dissimilarity captures residential segregation, measuring the degree of spatial separation of two population subgroups across neighbourhoods within a city ${ }^{28}$ and taking values between 0 and 100 (maximum segregation). For unemployment it is calculated as:

$$
\begin{aligned}
& \text { Index of dissimilarity } \\
& =0.5 \times \Sigma\left|\left(\mathrm{x}_{\mathrm{i}} / \mathrm{X}\right)-\left(\mathrm{y}_{\mathrm{i}} / \mathrm{Y}\right)\right| \times 100
\end{aligned}
$$

$\mathrm{x}_{\mathrm{i}}=$ number of unemployed residents in neighbourhood $\mathrm{i}$, $X=$ total number of unemployed people in all study neighbourhoods, $y_{i}=$ number of employed residents in neighbourhood i, $Y=$ total number of employed people in all study neighbourhoods.

The association between neighbourhood deprivation and self rated health was investigated using multilevel logistic regression models (MLwin v1.10, Institute of Education, London) built up sequentially:

$$
\begin{aligned}
& \text { Base model: } \log \pi_{\mathrm{ij}} / \mathrm{l}-\pi_{\mathrm{ij}}=\beta_{0} \text { London }_{\mathrm{ij}}+ \\
& \beta_{1} \text { Helsinki }_{\mathrm{ij}}+\beta_{2} \text { age }_{\mathrm{ij}}+\beta_{3} \operatorname{sex}_{\mathrm{ij}}+\mathrm{u}_{0 \mathrm{j}}+\mathrm{u}_{\mathrm{lj}} \\
& +\mathrm{e}_{\mathrm{ij}}
\end{aligned}
$$

$\pi_{\mathrm{ij}}=$ probability of $\mathrm{i}^{\text {th }}$ participant in $\mathrm{j}^{\text {th }}$ neighbourhood having less than good health, $\beta_{0}=\log$ odds of less than good health in London, $\beta_{1}=\log$ odds of less than good health in Helsinki, $\mathrm{u}_{0 \mathrm{j}}=$ difference in health in neighbourhood $\mathrm{j}$ compared with London average, and $\mathrm{u}_{1 \mathrm{j}}=$ difference in health in neighbourhood j compared with Helsinki average (all adjusted for age and sex). The model was fitted with an overall intercept for London $\left(\beta_{0}\right)$ and another for Helsinki $\left(\beta_{1}\right)$ and with random intercepts for each neighbourhood in London $\left(\mathrm{u}_{0 \mathrm{j}}\right)$ and in Helsinki $\left(\mathrm{u}_{1 \mathrm{j}}\right)$.

The total variation in self rated health is partitioned into that between neighbourhoods $\left(\sigma_{\mathrm{u} 0}{ }^{2}\right.$ in London and $\sigma_{\mathrm{ul}}{ }^{2}$ in Helsinki) and that within neighbourhoods. $\sigma_{\mathrm{u} 0}{ }^{2}$ and ${\sigma_{\mathrm{ul}}}^{2}$ can be interpreted through the intraclass correlation coefficient (ICC), which is the proportion of total variation in health that occurs between neighbourhoods.

Model 2: Base model + neighbourhood indicator as continuous score* + city x neighbourhood indicator interaction (separate model for each of the four indicators)

Model 3: Base model + neighbourhood indicator quartile

Model 4: Model $3+$ adjustment for individual socioeconomic position

Model 2 allows us to compare the health effect of a $1 \%$ increase in the level of the neighbourhood indicator in the two cities. For presentation, the models were repeated using quartiles of neighbourhood indicators. Effects of age, sex, and socioeconomic position were allowed to vary by city by the addition of interaction terms. Statistical significance was assessed using the Wald test. ${ }^{30}$

Ethical approval for human research was obtained for each study.

*The arcsine transformation was used to stabilise the variance of the neighbourhood proportions. 
Table 1 Distribution of neighbourhood indicators for 863 neighbourhoods in London and 223 neighbourhoods in Helsinki

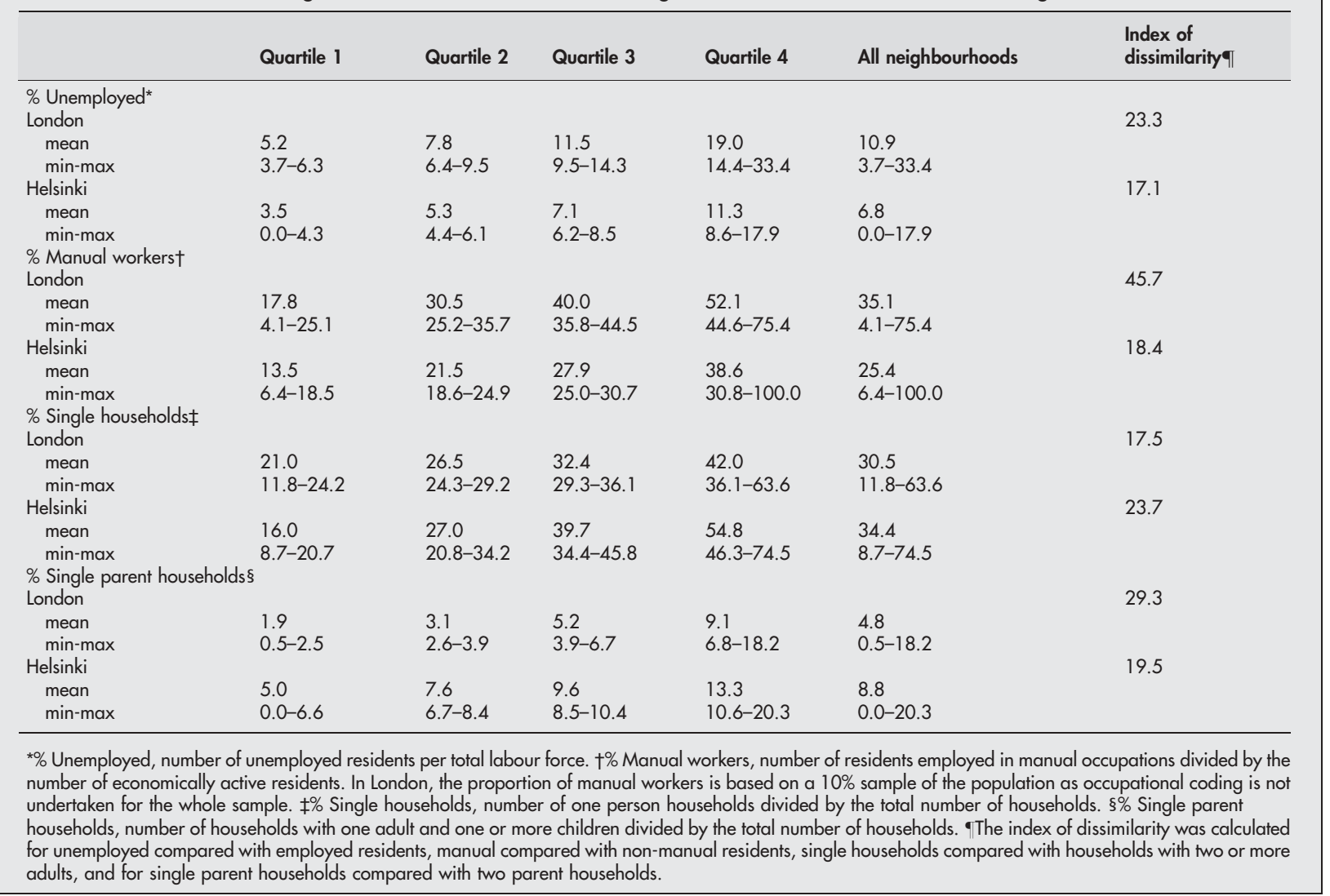

\section{RESULTS}

Unemployment was higher in London than in Helsinki and the difference in unemployment rate between the top and bottom quartiles was larger in London (table 1). This is reflected in a higher segregation index for employed compared with unemployed residents in London (23.3) compared with Helsinki (17.1) and similarly for manual compared with non-manual workers. The extent of socioeconomic separation was larger in London than in Helsinki. Single households were separated from multiple person households slightly more in Helsinki. Single parent households were separated from two parent households to a greater extent in London.

Table 2 summarises the study participants. An average of 6.1 participants per neighbourhood in London and 19.3 per neighbourhood in Helsinki had complete data. There were no manual workers in the London sample. In both cohorts, reporting of less than good self rated health increased with age and was slightly higher for women than for men. Participants in lower socioeconomic positions were more likely to report less than good health than those in higher positions. The social gradient was steeper in London. This was allowed for by including interaction terms between socioeconomic position and city (that is, study cohort).

There were no differential effects of neighbourhood unemployment, proportion of residents in manual occupations, or proportion of single households in Helsinki and London. In pooled data, residence in a neighbourhood with highest unemployment was associated with an age and sex adjusted odds ratio of less than good health of 1.78 (95\% CI 1.54 to 2.06) (table 3, model 3). Proportion of manual workers and single households were also associated with self rated health. Living in a neighbourhood with the highest proportion of single parent households was associated with a
$21 \%$ higher odds of reporting less than good health in Helsinki (OR 1.21, 95\% CI 0.97 to 1.50 ) and a $67 \%$ higher odds in London (OR $1.6795 \%$ CI 1.09 to 2.55) (test for interaction, $\mathrm{p}=0.006$ ).

Adjustment for individual socioeconomic position attenuated the effects of neighbourhood (table 3, model 4). Part of the increased odds of less than good health in neighbourhoods with highest unemployment was attributable to the lower employment grade of residents there. However, independent effects of neighbourhood unemployment remained. Modest effects of proportion of residents in manual occupations and proportion of single households also remained. A slightly larger effect of proportion of single parent households in London remained, but the test for interaction was not statistically significant. These data are suggestive of a small contextual effect of single parent households in London but not in Helsinki.

In the age and sex adjusted model, the variation between neighbourhoods in London was significant (Wald test $\mathrm{p}<0.01$ ) (table 4 ). In both cities, a relatively small proportion of the total variation in self rated health was between neighbourhoods (3\% in London and $0.4 \%$ in Helsinki). Adjustment for individual socioeconomic position reduced between neighbourhood variation to $2 \%$ of the total in London and $0.1 \%$ of the total in Helsinki. There was greater variation in self rated health between neighbourhoods in London, and this excess was not entirely attributable to greater spatial separation of high and low grade participants in London. Adjustment for neighbourhood indicators further reduced variation between neighbourhoods.

\section{DISCUSSION}

The spatial separation of residents in high and low socioeconomic positions was higher in London than in Helsinki. 
Table 2 Summary of characteristics of participants in the Whitehall II study (London) and the Helsinki health study (Helsinki)

\begin{tabular}{lll}
\hline & London & Helsinki \\
\hline Number of participants & 5301 & 4287 \\
Number of neighbourhoods & 863 & 223 \\
Population in neighbourhood & $\sim 8000$ & $\sim 4000$ \\
$\begin{array}{l}\text { Mean (min-max) number of study participants per } \\
\text { neighbourhood }\end{array}$ & $6(1-48)$ & $19(1-108)$ \\
Individual level data & & \\
Men (\%) & 61 & 21 \\
Age (mean (SD)) & $50(6)$ & $50(7)$ \\
Socioeconomic position (\%) & 31 & 32 \\
$\quad$ High non-manual & 46 & 18 \\
Middle non-manual & 23 & 36 \\
Low non-manual & 0 & 14 \\
Manual & 27 & 26 \\
Less than good self rated health (\%) & & \\
\hline
\end{tabular}

Income inequality is higher in the UK than in Finland and findings from the US show it is highly correlated with socioeconomic segregation $^{31} 32$ and so we hypothesised that segregation would be higher in London. We have shown this empirically and we suggest that policies aimed at preventing socioeconomic segregation in the Helsinki metropolitan area may have had some success when combined with national policies to reduce income inequality. Note though that residential segregation is greater in more populous places (although segregation in London is smaller than expected given its $\operatorname{size}^{33}$ ). London and Helsinki differ in population size as well as in policy approaches.

Between neighbourhood differences in self rated health were also greater in London. Other studies point to large health differences over small distances in London. Life expectancy in Westminster was five years higher than in Newham, six underground stations away. ${ }^{34}$ Both individual socioeconomic position and contextual effects (captured by unemployment rate, proportion of manual workers, single households, and single parent households) explained health differences between neighbourhoods. The spatial separation of residents may have emergent effects-at a certain level, the concentration of disadvantaged residents may begin to have effects on other residents irrespective of their own characteristics. This separation may affect health by isolating residents in lower social positions from economic opportunities, from groups with political power, and from potentially health enhancing public and private services that depend on local demand and local income, and/or by weakening social connections and social cohesion. ${ }^{35}$

This study provides further evidence that features of the residential environment are likely to be associated with self rated health, over and above individual characteristics. These contextual effects were small to moderate in size; residence in high unemployment neighbourhoods was associated with a $50 \%$ increase in the likelihood of reporting less than good

Table 3 Neighbourhood level influences on less than good self rated health in London and Helsinki. All models are adjusted for individual age and sex

\begin{tabular}{|c|c|c|}
\hline & \multirow{2}{*}{$\begin{array}{l}\text { Model 3: neighbourhood indicator } \\
\text { quartile } \\
\text { OR }(95 \% \mathrm{Cl})\end{array}$} & \multirow{2}{*}{$\begin{array}{l}\text { Model 4: Model } 3+\text { individual } \\
\text { socioeconomic position } \\
\text { OR }(95 \% \mathrm{Cl})\end{array}$} \\
\hline & & \\
\hline \multicolumn{3}{|l|}{ Proportion unemployed } \\
\hline Quartile 1 (lowest) & 1 & 1 \\
\hline 2 & 1.24 (1.07 to 1.44$)$ & 1.19 (1.03 to 1.38$)$ \\
\hline 3 & $1.38(1.19$ to 1.60$)$ & $1.25(1.08$ to 1.45$)$ \\
\hline 4 (highest) & $1.78(1.54$ to 2.06$)$ & 1.51 (1.30 to 1.75$)$ \\
\hline \multicolumn{3}{|c|}{ Proportion manual workers } \\
\hline Quartile 1 (lowest) & 1 & 1 \\
\hline 2 & 1.21 (1.06 to 1.38$)$ & 1.08 (0.95 to 1.24$)$ \\
\hline 3 & 1.42 (1.24 to 1.62$)$ & 1.19 (1.04 to 1.37$)$ \\
\hline 4 (highest) & $1.59(1.38$ to 1.83$)$ & 1.26 (1.08 to 1.46$)$ \\
\hline \multicolumn{3}{|c|}{ Proportion single households } \\
\hline Quartile 1 (lowest) & 1 & 1 \\
\hline 2 & 1.22 (1.05 to 1.43 ) & $1.20(1.03$ to 1.40$)$ \\
\hline 3 & $1.17(1.00$ to 1.35$)$ & $1.12(0.97$ to 1.30$)$ \\
\hline 4 (highest) & 1.32 (1.14 to 1.53$)$ & 1.31 (1.14 to 1.51$)$ \\
\hline \multicolumn{3}{|c|}{$\begin{array}{l}\text { Proportion single parent } \\
\text { households }\end{array}$} \\
\hline Quartile 1 (lowest) & 1 & 1 \\
\hline 2 & 1.05 (0.83 to 1.33 ) & $1.01(0.80$ to 1.28$)$ \\
\hline 3 & $1.16(0.94$ to 1.44$)$ & 1.03 (0.83 to 1.27 ) \\
\hline 4 (highest) & $1.21(0.97$ to 1.50$)$ & $1.06(0.85$ to 1.31$)$ \\
\hline London $\times$ quartile $1^{*}$ & $1.04(0.84$ to 1.30$)$ & 0.90 (0.73 to 1.12$)$ \\
\hline London $\times$ quartile 2 & $1.26(0.81$ to 1.95$)$ & $1.04(0.68$ to 1.61$)$ \\
\hline London $\times$ quartile 3 & $1.47(0.97$ to 2.22$)$ & 1.14 (0.75 to 1.72$)$ \\
\hline London $\times$ quartile 4 & $1.67(1.09$ to 2.55$)$ & $1.20(0.79$ to 1.84$)$ \\
\hline
\end{tabular}




\section{Key points}

- The spatial segregation of residents in high and low socioeconomic positions is greater in London than in Helsinki.

- Age and sex adjusted differences in self rated health between neighbourhoods are greater in London than in Helsinki.

- Over and above individual factors, indicators of neighbourhood deprivation are associated with self rated health in both cities.

- The greater between neighbourhood differences in health seen in London are partly attributable to spatial clustering of residents in high and low socioeconomic positions and partly attributable to neighbourhood socioeconomic context.

health. We found no difference in the magnitude of the deprivation health slope for three of the neighbourhood indicators. An association between proportion of single parent households and health was seen in London but was less evident in Helsinki. Although lone motherhood is likely to be a disadvantaged position also in Finland, lone mothers are almost as often employed as married mothers. In Britain, being a lone mother strongly reduces the likelihood of being employed. ${ }^{36}$ In Finland, the employment of women, including lone mothers, has been supported by social policies, for example by providing widely available and subsidised public childcare. The municipality is required by law to provide childcare for all children aged less than 3 years. A recent international comparison found a variety of ways to support families in Finland, but in Britain such supports are clearly below the OECD average level. ${ }^{37}$ A comparison of policies that may influence the health of lone parents indicates that Britain also lags behind Sweden. ${ }^{38}$ The correlation between

\section{Policy implications}

- Local and national welfare and planning policies may help to contain socioeconomic segregation and to restrict area inequalities in health.

proportion of single parent households and unemployment rate was 0.83 in London and 0.33 in Helsinki. These findings suggest that inadequate resources and opportunities for single parents may have implications not only for those single parents and their children but also for the wider population.

As a proportion of the total variation, variation between neighbourhoods was small. This may be partly attributable to low statistical power to estimate between neighbourhood variation. However, small differences in self rated health between neighbourhoods combined with the large and consistent effects of individual socioeconomic position on self rated health found here (data not shown) and in other studies ${ }^{22} 39$ highlight the importance of structural forces beyond the immediate neighbourhood that contribute towards shaping individual health.

This study was limited to public sector employees and is not representative of the general population. Neighbourhood effects may be smaller for employed participants who are less exposed to their neighbourhood and more exposed to other contexts (especially the workplace). Furthermore, some attrition in the Whitehall II sample means that participants included here were in higher socioeconomic positions than the original sample. Associations between neighbourhood characteristics and health seem to be less important for those in higher socioeconomic positions. ${ }^{40}$ The associations presented here may be conservative, especially for the London sample. However, as our investigation was restricted to public sector employees, participants in the two cities may be more similar on unmeasured variables, which may improve the

Table 4 Variation in less than good self rated health across neighbourhoods in London and Helsinki

\begin{tabular}{|c|c|c|}
\hline & London & Helsinki \\
\hline \multicolumn{3}{|l|}{ Base model: age and sex adjusted } \\
\hline Variance (SE) between neighbourhoods & $0.106(0.040)$ & $0.012(0.014)$ \\
\hline Variance (SE) within neighbourhoods & & \\
\hline $\mathrm{ICC}^{*}$ & 0.030 & 0.004 \\
\hline \multicolumn{3}{|l|}{ Age, sex, and socioeconomic position adjusted } \\
\hline Variance (SE) between neighbourhoods & $0.067(0.037)$ & $0.003(0.012)$ \\
\hline Variance (SE) within neighbourhoods & & \\
\hline ICC & 0.020 & 0.001 \\
\hline \multicolumn{3}{|l|}{ Adjusted for age, sex, SES, $+\%$ unemployed } \\
\hline Variance (SE) between neighbourhoods & $0.038(0.035)$ & $0.002(0.011)$ \\
\hline Variance (SE) within neighbourhoods & & \\
\hline ICC & 0.011 & 0.000 \\
\hline \multicolumn{3}{|c|}{ Adjusted for age, sex, SES, $+\%$ manual workers } \\
\hline Variance (SE) between neighbourhoods & $0.058(0.037)$ & $0.000(0.011)$ \\
\hline Variance (SE) within neighbourhoods & & \\
\hline ICC & 0.018 & 0.000 \\
\hline \multicolumn{3}{|c|}{ Adjusted for age, sex, $\mathrm{SES},+\%$ single households } \\
\hline Variance (SE) between neighbourhoods & $0.051(0.36)$ & $0.000(0.000)$ \\
\hline Variance (SE) within neighbourhoods & & \\
\hline ICC & 0.015 & 0.000 \\
\hline \multicolumn{3}{|c|}{ Adjusted for age, sex, SES, $+\%$ single parent households } \\
\hline Variance (SE) between neighbourhoods & $0.059(0.037)$ & $0.008(0.013)$ \\
\hline Variance (SE) within neighbourhoods & & \\
\hline ICC & 0.018 & 0.002 \\
\hline
\end{tabular}

*Intraclass correlation coefficient (the proportion of the total variance in self rated health that is between neighbourhoods) is estimated as $\sigma_{\mathrm{u}}{ }^{2}$ divided by $\left(\sigma_{\mathrm{vO}}{ }^{2}+\pi^{2} / 3\right)$ and ranges from 0 (no differences in self rated health between neighbourhoods) and 1 (all variation is at the neighbourhood level). 
precision with which neighbourhood effects can be detected and compared. Two other sources of bias may also lead to underestimation of the differences between London and Helsinki neighbourhoods. Neighbourhood data from London were collected in 1991, and from Helsinki in 2001. Geographical variations in health have increased in the UK over the past 10 years so we might expect a comparison of the two cities in 2001 to show larger differences than found here. Additionally, within neighbourhood heterogeneity tends to increase (and between neighbourhood differences to decrease) with neighbourhood population size. If it were possible to use smaller neighbourhoods in London then greater differences between London neighbourhoods may be found.

Residual confounding by individual socioeconomic position may induce spurious associations at the neighbourhood level. Employment grade is shown to be a strong and consistent predictor of morbidity in the Whitehall II and Helsinki health studies. ${ }^{92}{ }^{41-43}$ While we cannot ignore the possibility that employment grade does not capture a person's economic wellbeing completely, evidence suggests it is a good indicator in these working cohorts.

This study used neighbourhood indicators based on administrative data that are proxies for factors such as facilities and services, physical hazards, and employment opportunities that are thought to influence health. The four indicators were studied separately rather than as a summary index in order to identify which indicators were important for health in London and Helsinki. Comparative studies such as this can highlight points for further workfurther exploration of the different policies towards single parents and their implications for parents and for wider society is indicated. This needs to be followed up with direct measurement of specific features of the residential context. ${ }^{44}$

In summary, differences in the prevalence of less than good self rated health across neighbourhoods were larger in London than in Helsinki. Greater separation of residents in high and low socioeconomic positions in London may have emergent effects at the neighbourhood level. As with all comparative studies of public policy, there are many historical and current differences that lie outside the immediate remit of government and that cannot be controlled for. ${ }^{45}$ Nevertheless, our findings suggest that local and national social policies may help reduce, or at least restrict, inequality and segregation along socioeconomic lines.

\section{ACKNOWLEDGEMENTS}

Thanks to members of the European Science Foundation Network on Social Variations in Health Expectancy in Europe Working Group III for their comments on earlier drafts; Petteri Sipilä and Netta Mäki for their help in preparing the data; and participants of the Whitehall II study and the Helsinki health study for their continued contributions to these studies. The Whitehall II study has been funded by the Medical Research Council, British Heart Foundation; Health and Safety Executive; Department of Health; National Heart Lung and Blood Institute (HL36310), US, NIH: National Institute on Aging (AG13196), US, NIH; Agency for Health Care Policy Research (HS06516); and the John D and Catherine T MacArthur Foundation Research Networks on Successful Midlife Development and Socio-economic Status and Health. The Helsinki health study is supported by grants from the Academy of Finland, Research Council for Health (48119, 48553 and 53245) and the Finnish Work Environment Fund (99090). PM is funded by the Academy of Finland $(70631,48600)$.

\section{Authors' affiliations}

M Stafford, P Martikainen, M Marmot, International Centre for Health and Society, Department of Epidemiology and Public Health, University College London Medical School, London, UK
P Martikainen, Population Research Unit, Department of Sociology, University of Helsinki, Finland

E Lahelma, Department of Public Health, University of Helsinki, Finland

Conflicts of interest: none declared.

\section{REFERENCES}

1 Duncan C, Jones K, Moon G. Health-related behaviour in context: a multilevel modelling approach. Soc Sci Med 1996 Mar;42:817-30.

2 Kaplan GA. People and places: contrasting perspectives on the association between social class and health. Int J Health Serv 1996;26:507-19.

3 O'Campo P, Xue X, Wang MC, et al. Neighborhood risk factors for low birthweight in Baltimore: a multilevel analysis. Am J Public Health 1997;87:1113-18.

4 Diez-Roux AV, Nieto FJ, Muntaner C, et al. Neighborhood environments and coronary heart disease: a multilevel analysis. Am J Epidemiol 1997; 146:48-63.

5 Wiggins RD, Bartley M, Gleave S, et al. Limiting long-term illness: a question of where you live or who you are? A multilevel analysis of the 1971-1991 ONS longitudinal study. Risk Decision and Policy 1998;3:181-98.

6 Yen IH, Kaplan GA. Poverty area residence and changes in physical activity level: evidence from the Alameda County study. Am J Public Health 1998;88:1709-12.

7 Robert SA. Community-level socioeconomic status effects on adult health. J Health Soc Behav 1998;39:18-37.

8 Soobader MJ, LeClere FB. Aggregation and the measurement of income inequality: effects on morbidity. Soc Sci Med 1999;48:733-44.

9 Bosma H, van de Mheen HD, Borsboom GJ, et al. Neighborhood socioeconomic status and all-cause mortality. Am J Epidemiology $2001 ; 153: 363-71$.

10 Martikainen P, Kauppinen TM, Valkonen T. Effects of the characteristics of neighbourhoods and the characteristics of people on cause specific mortality: a register based follow up study of 252000 men. J Epidemiol Community Health 2003;57:210-17.

11 Macintyre S, Maciver S, Sooman A. Area, class and health: should we be focusing on places or people? Journal of Social Policy 1993;22:213-34.

12 Jerrett M, Eyles J, Cole D. Socioeconomic and environmental covariates of premature mortality in Ontario. Soc Sci Med 1998;47:33-49.

13 Bourne LS. Close together and worlds apart: an analysis of changes in the ecology of income in Canadian cities. Urban Studies in the ecology of income

14 Ross N, Wolfson M, Dun J, et al. Relation between income inequality and mortality in Canada and in the United States: cross-sectional assessment using census data and vital statistics. BMJ 2000;320:898-902.

15 Office for National Statistics. Census 2001. http://www.statistics.gov.uk/ census $2001 /$ pyramids/pages/1b.asp

16 Ordnance Survey. Crown copyright 1992. http://census.ac.uk/cdu/gopher/ censushelp/helpfile/hectare/glndi.hectares.htm.

17 Greater London Authority. Health in London. Review of the London Health Strategy high level indicators. London: London Health Commission, 2003.

18 Morris J, Winn M. Housing and social inequality. London: Hilary Shipman, 1990:164-5.

19 Helsinki Region. Statistical comparisons. Helsinki: City of Helsinki Urban Facts, 2002.

20 Korhonen E. Challenges to municipal rented housing in Helsinki. In: Taipale K, Schulman H, eds. Home in Helsinki. The future of urban housing. Helsinki: Helsingin kaupungin tietokeskus, 1997.

21 Atkinson A, Rainwater L, Smeeding T. Income distribution in OECD countries. Paris: OECD Social Policy Studies 18, 1995.

22 Marmot MG, Davey Smith G, Stansfeld S, et al. Health inequalities among British civil servants: the Whitehall II study. Lancet 1991;337:1387-93.

23 Lallukka T, Aittomäki A, Piha K, et al. The representativeness of mail survey data by socioeconomic factors and sickness absence: the Helsinki Health Study. [In Finnish]. Sosiaalilääk Aikak 2002;39:164-71.

24 Manderbacka K. Examining what self-rated health question is understood to mean by respondents. Scand J Soc Med 1998;26:145-53.

25 Martikainen $\mathbf{P}$, Aromaa A, Heliovaara M, et al. Reliability of perceived health by sex and age. Soc Sci Med 1999;48:1117-22.

26 Idler EL, Benyamini Y. Self-rated health and mortality: a review of twentyseven community studies. J Health Soc Behav 1997;38:21-37.

27 de Bruin A, Picavet HS, Nossikov A. Health interview surveys. Towards international harmonization of methods and instruments. WHO Reg Publ Eur Ser 1996;58:1-161

28 Collins CA, Williams DR. Segregation and mortality: the deadly effects of racism? Sociological Forum 1999;14:495-523.

29 Reference withdrawn.

30 Goldstein H. Multilevel statistical models. London: Arnold, 1995:33-5.

31 Massey DS. The age of extremes: concentrated affluence and poverty in the twenty-first century. Demography 1996;33:395-412.

32 Lobmayer $\mathbf{P}$, Wilkinson RG. Inequality, residential segregation by income, and mortality in US cities. J Epidemiol Community Health 2002;56:183-7.

33 Gordon I, Monastiriotis V. Urban size, spatial segregation and educational outcomes. LSE Research Paper in Spatial and Environmental Analysis, 87. London: London School of Economics, 2003.

34 Fitzpatrick J, Jacobson B. Mapping health inequalities across London. London: London Health Observatory, 2001:7-9. 
35 Ross NA, Nobrega K, Dunn J. Income segregation, income inequality and mortality in North American metropolitan areas. GeoJournal $2001 ; 53: 117-24$ 36 Lahelma E, Arber S, Kivela K, et al. Multiple roles and health among British and Finnish women: the influence of socioeconomic circumstances. Soc Sci Med 2002;54:727-40.

37 Forssen K. Children, families and the welfare state. Helsinki: Stakes Research Reports no 92, 1998.

38 Whitehead M, Burstrom B, Diderichsen F. Social policies and the pathways to inequalities in health: a comparative analysis of lone mothers in Britain and Sweden. Soc Sci Med 2000:50:255-70.

39 Power C, Matthews S, Manor O. Inequalities in self rated health in the 1958 birth cohort: lifetime social circumstances or social mobility? BMJ 1996;313:449-53.

40 Stafford M, Marmot M. Neighbourhood deprivation and health: does it affect us all equally? Int J Epidemiol 2003;32:357-66.
41 Hemingway $\mathrm{H}$, Stafford M. Stansfeld S, et al. Is the SF-36 a valid measure of change in population health? Results from the Whitehall II study. BMJ 1997;315:1273-9.

42 Martikainen PT, Marmot MG. Socioeconomic differences in weight gain and determinants and consequences of coronary risk factors. Am J Clin Nutr 1999:69:719-26

43 Lahelma E, Martikainen $P$, Laaksonen $M$, et al. Pathways between socioeconomic determinants of health. J Epidemiol Community Health 2004;58:327-32.

44 Macintyre S, Ellaway A, Cummins S. Place effects on health: how can we conceptualise, operationalise and measure them? Soc Sci Med 2002;55:125-39.

45 Tuohy CH. Accidental logics. The dynamics of change in the health care arena in the United States, Britain, and Canada. New York: Oxford University Press, 1999.

\section{THE JECH GALLERY}

\section{Children, housing, and health: from Glasgow slums to displaced persons}

7 he link between poor housing, environmental conditions, and health has been long established. ${ }^{1}$ In Glasgow, one of the worst areas of slum housing was in the Gorbals. The photograph on the left, taken around 1925, shows a young woman at a communal sink in a backcourt, behind her the door to an outside toilet. At the back of courtyard, rubbish is piling up in the midden. Overcrowding was a major problem with large families squeezed into one and two roomed houses. In 1931, almost 85000 people lived in this area of Glasgow, which covered only $2 \%$ of the city's total territory. ${ }^{2}$ These conditions led, as in other parts of the UK, to the extensive slum clearance programmes of the 1950s and 1960s.

Contrast this with the second picture, taken in the Gaza Buildings, Beirut, Lebanon in 2003. Here, Palestinian families displaced from the official Shatila camp in 1985 during the "war of the camps", and their descendants, have made their home. Home, in this case, is the bomb damaged buildings of the former Gaza hospital. Overcrowding is rife, with families forced to subdivide accomodation units into smaller and smaller living spaces to accommodate new generations of the family. The small boy is pictured in front of his home, built in the backcourt of one of the buildings from corrugated iron panels. What are his life chances?

Catherine A O'Donnell, Graham C M Watt General Practice and Primary Care, Division of Community-based Sciences, University of Glasgow, Glasgow, UK
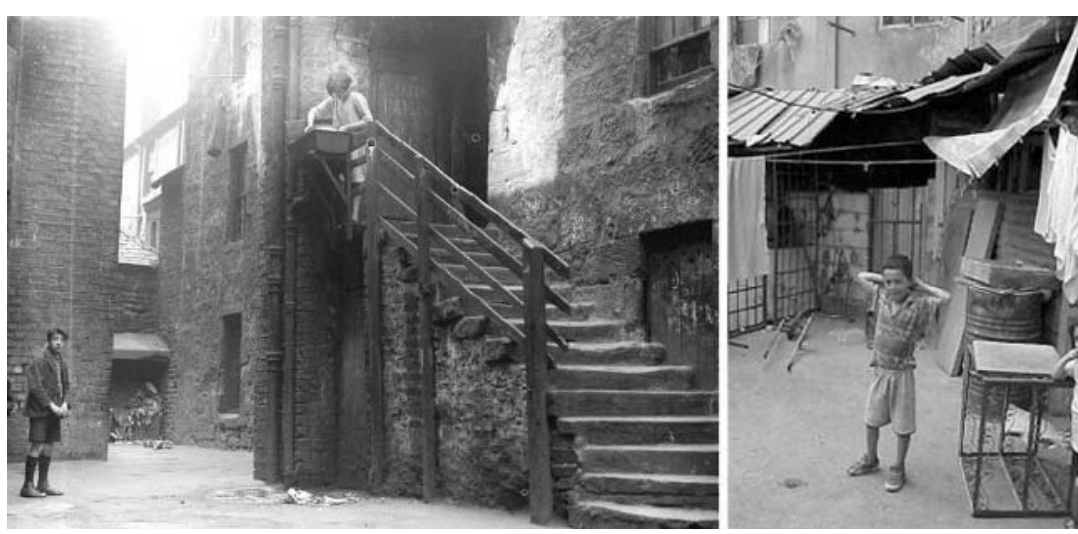

The photograph of the Gorbals is copyright of Glasgow City Archives.

Jumanah E Zabaneh

Green Line Association, Beirut, Lebanon

Correspondence to: $\operatorname{Dr} C$ A O'Donnell, General Practice and Primary Care, Division of Communitybased Sciences, University of Glasgow, 1 Horselethill Road, Glasgow G12 9LX, UK; Kate.O'Donnell@clinmed.gla.ac.uk

\section{REFERENCES}

1 Chadwick E. In: Flinn WM, ed. Report on the sanitary condition of the labouring population of Great Britain. Edinburgh: Edinburgh University Press, 1965 (First published in 1842)

2 TheGlasgowStory. http://www.theglasgowstory.com/ 